\title{
The influence of multi-morbidity and self-reported socio-economic standing on the prevalence of depression in an elderly Hong Kong population
}

\author{
Samuel YS Wong ${ }^{1}$, Stewart W Mercer*4, Jean Woo $^{2}$ and Jason Leung ${ }^{3}$
}

Address: ${ }^{1}$ Department of Community \& Family Medicine, The Chinese University of Hong Kong, 4/F, School of Public Health, Prince of Wales Hospital, Shatin, N.T., Hong Kong, ${ }^{2}$ Department of Medicine \& Therapeutics, The Chinese University of Hong Kong, 9/F, Clinical Sciences Building, Prince of Wales Hospital, Shatin, N.T., Hong Kong, ${ }^{3}$ Jockey Club Center for Osteoporosis Care and Control, The Chinese University of Hong Kong, 3/F, School of Public Health, Prince of Wales Hospital, Shatin, N.T., Hong Kong and ${ }^{4}$ General Practice and Primary Care, Division of Community-Based Sciences, Faculty of Medicine, University of Glasgow, UK

Email: Samuel YS Wong - yeungshanwong@cuhk.edu.hk; Stewart W Mercer* - stewmercer@cuhk.edu.hk; Jean Woo - jeanwoowong@cuhk.edu.hk; Jason Leung - jason-leung@cuhk.edu.hk

* Corresponding author

Published: 14 April 2008

BMC Public Health 2008, 8:119 doi:10.1 I86/147|-2458-8-119
Received: 16 October 2007

Accepted: 14 April 2008

This article is available from: http://www.biomedcentral.com/I47I-2458/8/II9

(c) 2008 Wong et al; licensee BioMed Central Ltd.

This is an Open Access article distributed under the terms of the Creative Commons Attribution License (http://creativecommons.org/licenses/by/2.0), which permits unrestricted use, distribution, and reproduction in any medium, provided the original work is properly cited.

\begin{abstract}
Background: There has been an increasing prevalence of both depression and chronic medical conditions globally but the relationship between depression and multi-morbidity is not well understood. The aim of the present study was to investigate the relationship between depression, multi-morbidity (number of chronic medical conditions, and measures of socioeconomic standing (SES) in an elderly Hong Kong population.
\end{abstract}

Methods: Cross sectional study. Information on clinically relevant depressive symptoms, measured by the Geriatric Depression Scale (GDS), and demographic and chronic medical conditions were collected using standardized questionnaires. Information collected on SES included educational status (ES), maximum ever income (MEI), and self-perceived social standing in local community (SES-COM) and in Hong Kong generally (SES-HK). Analysis was conducted using multiple logistic regression

Results: Depression rates were similar in men and women (GDS caseness $8.1 \%$ vs $8.4 \%$ ). Multimorbidity of chronic medical conditions was common ( $40 \%$ of men and $46 \%$ of women had three or more). In the overall sample, the prevalence of depression was associated with the number of chronic medical conditions (OR I.27; Cl: I.16-I.39). In addition, SES-HK and SES-COM were significant independent variables.

Conclusion: In this elderly Hong Kong population, depression prevalence rose markedly with number of chronic medical conditions and SES-HK and SES-COM.

\section{Background}

Mental illness is a significant public health problem worldwide. According to the World Health Organization [1], by 2010, depression will be the second most impor- tant condition globally in terms of disability (Disability Adjusted Life Years). It will also be the disease with the greatest burden on society in developed countries [1]. 
Mental health problems, physical conditions and socioeconomic status appear to be closely related in many societies [2-4]. For people with low socioeconomic status, association with increased morbidity and mortality rates have been documented $[3,4]$. Patients with chronic medical conditions are at increased risk of significant psychological distress including depression, resulting in role functioning impairment [5-8], increase in treatment costs [9], decrease in compliance with medical regimens [10] and worsened disease course leading to higher mortality and disability $[11,12]$. In the area of mental health, patients with low socioeconomic status or those who live in deprived areas often have a higher prevalence and incidence of depression and psychological distress [13-15]. Although these associations between depression and chronic diseases are well recognized [16], the possible synergistic influence of co-morbidity and deprivation on psychological distress is less well documented $[17,18]$.

In Hong Kong, studies conducted in the elderly have demonstrated a significant association between depressive symptoms and a number of different chronic conditions including osteoporosis [19], chronic obstructive pulmonary diseases [20], lower urinary tract symptoms [21] and stroke [22]. The current study was conducted to investigate the relationship between both objective and subjective socio-economic standing, multi-morbidity, and depression in an elderly Chinese population.

\section{Methods}

Data from 3394 men and women aged 65 years and over who were parts of a study on risk factors of osteoporosis were used in the current study. Subjects were recruited by placing notices in community centres for the elderly and housing estates, followed by talks that explained the purpose, procedures and investigations of the study. Subjects were volunteers with the aim to recruit a stratified sample so that approximately 33\% were in each of these age groups: 65-69, 70-74, 75+. The study was approved by the Clinical Research Ethics Committee of the Chinese University of Hong Kong, which requires written informed consent to be obtained.

A questionnaire containing information regarding demographics, socioeconomic status, medical history, self perceived social standing and depressive symptoms was administered by a trained interviewer. The presence or absence of disease was based on subjects' report of diagnosis by their doctors on 14 common chronic medical conditions (LTC). Socio-economic status was assessed both subjectively and objectively. For subjects' self perceived socioeconomic status, an instrument developed by the John D and Catherine T. MacArthur Research Network on Socioeconomic Status and Health was used (Adler et al, 2000). Subjects were asked to place a mark on an upright ladder with ten rungs, with the lowest rung being the most undesirable and the highest the most desirable state with respect to their standing in the community (community ladder). At the same time, they were also asked to rate themselves by placing a mark on another ladder, the top rung representing people who have the most money, the most education, and the most respected jobs, and the bottom rung representing people at the other extreme (Hong Kong ladder). Education levels and the highest income ever obtained were used as the measure for objective socioeconomic status. Clinically significant depressive symptoms were measured using the validated Chinese version of Geriatric Depression Scale [23] with a cut off score of 8 indicative of clinically relevant depressive symptoms. In the study conducted by Lee et al. [23], the 8 -symptom cut off point yielded $96 \%$ sensitivity and $87.5 \%$ specificity for a DSM-based clinician diagnosis of depression.

\section{Statistical Analysis}

The means of variables between men and women were compared by two sample t-tests for continuous variables and chi-squared tests for categorical variables. The associations between number of chronic medical conditions, SES and depression were studied using independent t-test for continuous variables and chi-squared tests for categorical variables. To study factors associated with depression, logistic regression analysis was conducted to study the independent effects of age, number of chronic medical conditions, marital status, education levels, maximum incomes and self perceived SES on clinically relevant depressive symptoms. All statistical analyses were performed using the statistical package SAS, version 8.02 (SAS Institute, Inc., Cary, North Carolina).

\section{Results}

The characteristics of the overall sample are shown in Table 1 . The age distribution was fairly evenly divided between the three age groups $(65-69,70-74,75$ or above) and was similar for men and women. Depression scores and prevalence rates were similar in men and women with approximately 1 in 12 subjects reaching GDS-caseness. Multi-morbidity was common in both genders but more women reported three or more chronic medical conditions than men (46\% versus $40 \%$ ). Significant differences existed between men and women in terms of marital status, with more women being widowed. Educational level and maximum income were also markedly lower in women than men. Self-perceived SES also differed with gender, with men reporting lower SES-HK and SES-COM than women, despite their higher educational status and maximum income. This gender difference was most marked for SES-COM. 
Table I: Characteristics of the sample that include gender, age, number of chronic diseases, socio-economic factors and depression

\begin{tabular}{|c|c|c|c|c|}
\hline \multirow[b]{2}{*}{ Variables } & \multicolumn{3}{|c|}{ Prevalence/Mean(SD) } & \multirow[b]{2}{*}{ p-value* } \\
\hline & Total $(n=3394)$ & Male $(n=1901)$ & Female $(n=1493)$ & \\
\hline Male & $190 \mid(56.0 \%)$ & & & \\
\hline Female & I 493 (44.0\%) & & & \\
\hline Age & & & & 0.1061 \\
\hline $65-69$ & $121 \mid(35.7 \%)$ & $649(34.1 \%)$ & $562(37.6 \%)$ & \\
\hline $70-74$ & 1204 (35.5\%) & $689(36.2 \%)$ & $515(34.5 \%)$ & \\
\hline 75 or above & $979(28.9 \%)$ & $563(29.6 \%)$ & $416(27.9 \%)$ & \\
\hline Geriatric Depression Scale & $2.9(2.8)$ & $2.9(2.8)$ & $2.8(2.7)$ & 0.2322 \\
\hline Depression (GDS score $\geq 8$ ) & $280(8.3 \%)$ & 154 (8.1\%) & $126(8.4 \%)$ & 0.7221 \\
\hline No. of chronic diseases & & & & $<.0001$ \\
\hline 0 & $355(10.5 \%)$ & $242(12.7 \%)$ & $113(7.6 \%)$ & \\
\hline I & $733(21.6 \%)$ & $4 I I(21.6 \%)$ & $322(21.6 \%)$ & \\
\hline 2 & $867(25.6 \%)$ & $491(25.8 \%)$ & $376(25.2 \%)$ & \\
\hline 3 or more & 1439 (42.4\%) & 757 (39.8\%) & $682(45.7 \%)$ & \\
\hline Current marital status & & & & $<.0001$ \\
\hline Married or living in a married-like relationship & $254 \mid(74.9 \%)$ & $1680(88.4 \%)$ & $861(57.7 \%)$ & \\
\hline Widowed & 705 (20.8\%) & $144(7.6 \%)$ & $56 \mid(37.6 \%)$ & \\
\hline Separated & $44(1.3 \%)$ & $21(1.1 \%)$ & $23(1.5 \%)$ & \\
\hline Divorced & $33(1.0 \%)$ & $15(0.8 \%)$ & $18(1.2 \%)$ & \\
\hline Single, never married & $71(2.1 \%)$ & $41(2.2 \%)$ & $30(2.0 \%)$ & \\
\hline Education level & & & & $<.0001$ \\
\hline No education & $494(14.6 \%)$ & $82(4.3 \%)$ & $412(27.6 \%)$ & \\
\hline Primary or below & $179 \mid(52.8 \%)$ & $1040(54.7 \%)$ & 751 (50.3\%) & \\
\hline Secondary or above & 1109 (32.7\%) & $779(41.0 \%)$ & $330(22.1 \%)$ & \\
\hline Max income a & & & & $<.0001$ \\
\hline $0-1999$ & $596(23.3 \%)$ & $145(9.1 \%)$ & $45 \mathrm{I}(46.6 \%)$ & \\
\hline $2000-5999$ & $579(22.6 \%)$ & $292(18.4 \%)$ & $287(29.7 \%)$ & \\
\hline $6000-11999$ & $688(26.9 \%)$ & $541(34.1 \%)$ & $147(15.2 \%)$ & \\
\hline 12000 or above & $694(27.1 \%)$ & $611(38.5 \%)$ & $83(8.6 \%)$ & \\
\hline SES ladder - Hong Kong & $4.5(1.9)$ & $4.5(1.8)$ & $4.7(1.9)$ & 0.0016 \\
\hline SES ladder - community & $6.8(2.2)$ & $6.3(2.2)$ & $7.3(2.1)$ & $<.0001$ \\
\hline
\end{tabular}

*p-value of $t$ test for continuous variables or chi square for categorical variables where appropriate, comparing male with female a Sample size for male was 1589 (missing value due to 36 refused and 276 don't know), sample size for female was 968 (missing value due to 138 housewife, 6 refused and 38I don't know)

The association of the number of chronic medical conditions with depression and SES is shown in Table 2. In this sample, depression prevalence rose sharply with the number of chronic medical conditions. Depression prevalence was significantly associated with all measures of SES in this sample (Table 2).

These univariate correlations confirmed the significant relationship between depression and the number of chronic medical conditions and the relationship between depression and all measures of SES.

Marital status and maximum income were significantly associated with the prevalence of depression. However, these relationships disappeared when SES-COM and SESHK were entered into the regression.

\section{Discussion}

Main findings

In the present study the relationship between multi-morbidity, objective and subjective socioeconomic status, and depressive symptoms were explored. We found significant associations between multi-morbidity and depressive symptoms and between SES and depressive symptoms. Although associations between individual chronic medical conditions and depression are well known [19$21,23,24]$, fewer studies have explored multi-morbidity and depression. We found that there was approximately an increased odds of having clinically relevant depressive symptoms when the number of chronic medical condition increases. Previous work in this area has suggested that it is the severity of the illness (the effect on the person's life) rather than the number of diseases that links 
Table 2: Logistic regression of gender, age, number of chronic medical conditions, social factors on depression

\begin{tabular}{|c|c|c|c|c|c|c|}
\hline \multirow[t]{2}{*}{ Variable } & \multirow[t]{2}{*}{$\mathbf{N}$} & \multicolumn{2}{|c|}{ Freq. (\%)/Mean (SD) } & \multirow{2}{*}{$\begin{array}{l}\text { Crude Odds ratio } \\
\text { (95\% Cl) }\end{array}$} & \multirow{2}{*}{$\begin{array}{l}\text { Adj. Odds ratio ( } 95 \% \\
\text { CI) of model }\end{array}$} & \multirow{2}{*}{$\begin{array}{l}\text { Adj. Odds ratio (95\% } \\
\text { CI) of model } 2^{2}\end{array}$} \\
\hline & & Controls & Depressed & & & \\
\hline $\mathrm{N}$ & 3394 & $3114(91.8 \%)$ & $280(8.2 \%)$ & & & \\
\hline \multicolumn{7}{|l|}{ Sex } \\
\hline Male & 1901 & 1747 (91.9\%) & 154 (8.1\%) & I & I & I \\
\hline Female & 1493 & 1367 (91.6\%) & $126(8.4 \%)$ & $1.05(0.82,1.34)$ & $0.69(0.47,1.02)$ & $1.27(0.83,1.94)$ \\
\hline \multicolumn{7}{|l|}{ Age } \\
\hline $65-69$ & $121 \mid$ & $1118(92.3 \%)$ & $93(7.7 \%)$ & I & I & I \\
\hline $70-74$ & 1204 & $1111(92.3 \%)$ & $93(7.7 \%)$ & I.0I $(0.75,1.36)$ & $0.78(0.54,1.13)$ & $0.75(0.50,1.12)$ \\
\hline 75 or above & 979 & $885(90.4 \%)$ & $94(9.6 \%)$ & $1.28(0.95,1.72)$ & $0.94(0.64,1.39)$ & $1.03(0.67,1.56)$ \\
\hline No. of chronic diseases* & 3394 & $2.3(1.6)$ & $3.1(1.7)$ & $1.27(1.19,1.36)$ & $1.29(1.19,1.41)$ & $1.27(1.16,1.39)$ \\
\hline \multicolumn{7}{|l|}{ Current marital status } \\
\hline $\begin{array}{l}\text { Married or living in a } \\
\text { married-like relationship }\end{array}$ & 2541 & $2358(92.8 \%)$ & $183(7.2 \%)$ & 1 & 1 & 1 \\
\hline $\begin{array}{l}\text { Single/Divorced/ } \\
\text { separated/widowed }\end{array}$ & 853 & $756(88.6 \%)$ & 97 (11.4\%) & $1.65(1.28,2.14)$ & $1.72(1.20,2.47)$ & $1.43(0.97,2.12)$ \\
\hline \multicolumn{7}{|l|}{ Education level } \\
\hline No education & 494 & 445 (90.1\%) & $49(9.9 \%)$ & I & I & I \\
\hline Primary or below & $179 \mid$ & $1626(90.8 \%)$ & $165(9.2 \%)$ & $0.92(0.66,1.29)$ & $0.97(0.6 \mathrm{I}, \mathrm{I} .53)$ & $0.95(0.58,1.58)$ \\
\hline Secondary or above & 1109 & $1043(94.1 \%)$ & $66(6.0 \%)$ & $0.57(0.39,0.85)$ & $0.75(0.44,1.25)$ & $1.00(0.57,1.77)$ \\
\hline \multicolumn{7}{|l|}{ Max income } \\
\hline $0-1999$ & 596 & 545 (9l.4\%) & $5 \mathrm{I}(8.6 \%)$ & I & I & I \\
\hline $2000-5999$ & 579 & $520(89.8 \%)$ & $59(10.2 \%)$ & $1.21(0.82,1.80)$ & $1.18(0.78,1.78)$ & $1.07(0.68,1.67)$ \\
\hline $6000-11999$ & 688 & $632(91.9 \%)$ & $56(8.1 \%)$ & $0.95(0.64, I .4 I)$ & $0.97(0.6 \mathrm{I}, \mathrm{I} .53)$ & $1.07(0.66,1.74)$ \\
\hline 12000 or above & 694 & $664(95.7 \%)$ & $30(4.3 \%)$ & $0.48(0.30,0.77)$ & $0.52(0.30,0.90)$ & $0.71(0.40,1.26)$ \\
\hline SES ladder - HK* & 3394 & $4.7(1.8)$ & $3.3(1.8)$ & $0.65(0.60,0.70)$ & - & $0.75(0.67,0.83)$ \\
\hline SES ladder - community* & 3394 & $6.9(2.1)$ & $5.2(2.6)$ & $0.7 \mathrm{I}(0.67,0.76)$ & - & $0.76(0.70,0.82)$ \\
\hline
\end{tabular}

*odd ratio representing per I unit increase

Imodel I includes all variables except SES ladders

${ }^{2}$ model 2 includes all variables

multi-morbidity with depression [16] and further work is required to link number and type of disease with severity and depression in the current sample. Literature on the impact of social factors such as social support is an important risk factor for depression $[25,26]$.

In terms of the importance of self-perceived SES, Cheng et al [27] investigated the association between self perceived SES and health outcome and showed that self perceived SES may be a more relevant measure for predicting health outcomes in the elderly, particularly for mental health status. Previous studies $[27,28]$ have also shown that the subjective experience of financial strain may be more closely related to health than objective measures of SES. Skapinakis et al. [29] demonstrated that subjective financial strain at baseline was independently associated with depression at follow up in a cohort. Others $[2,28,30]$ have found that differences in relative income standing correlates with health outcomes (including disability, self rated health and psychological functioning) and the effects can be more consistent and stronger with subjective measures of SES than objective indices of SES. Several mechanisms can explain the association between self perceived SES and clinically relevant depressive symptoms [29] that included lack of social support, lack of control over one's environment or chronic stress. Unfavorable social comparison with others [31] can also cause negative effects on mental health.

In Chinese elderly, using the same measure for subjective SES as in the present study, Hu et al. [3] found a positive association between the subjective ranking on the social hierarchy and self rated health and physical functioning. Of interest the present study was the finding that men reported lower SES-HK and SES-COM than that of women, despite their higher education and higher maximum income. This may be related to the cultural expectations and social role of women in this Chinese society.

To summarize the context of the present study, there is a dearth of studies in the international literature that specifically explore the relation between SES, multi-morbidity and depression. As far as we are aware, our study is the first to show a significant relationship between self-perceived SES, multi-morbidity and clinically important depressive symptoms in Chinese elderly. Our findings 
also add new information on the relationship between self perceived SES measured by the SES ladder, multi-morbidity and clinically relevant depressive symptoms in Chinese elderly.

\section{Implications for policy and practice}

Our results have implications for policy and practice. By studying the increase of the number of medical conditions and its relation to the risk of depression, we provide clinicians with information that can help them better identify those patients with multi-morbidity who are most at risk for depression. We also showed that those with both low SES and multi-morbidity are at the highest risk for depression.

As low self-perceived SES was shown to correlate strongly with depressive symptoms, health policy that can reduce inequity may decrease the impact of multi-morbidity on depressive symptoms. As we are reaching a point where both developed and developing countries suffer from a large burden on non-communicable diseases and disability resulting from mental disorders, any measures that can decrease the impact of non-communicable diseases and mental disorders can reduce the health burden on society. Health promotion and prevention programs that aim to increase social network and self perceived community standing and social interventions and health promotion that decrease chronic disease burden and increase financial support may all be relevant to decrease depression in the elderly population.

\section{Limitations}

One of the major limitations in our study is that this is a cross sectional study. As a result, no causal relationship can be established between SES, multi-morbidity and depression. It can be argued that depression can also cause a downward mobility effects on SES, although most studies conducted have not supported such a contention. Moreover, the directionality of the relationship between self perceived SES and depression is not known and some may argue that depression can cause low self esteem which may affect one's perception of social economic standing in both community and society.

Second, our study relied on self report of chronic medical conditions. As a result, under diagnosis of diseases and misclassification of disease status could not be excluded. However, as we did not study the relationship between specific types of disease and depressive symptoms, misclassification of disease should not significantly affect our results.

Third, we only used a validated scale to measure clinically relevant depressive symptoms, as a result, our results are only relevant to depressive symptoms and not depression per se.

\section{Conclusion}

We found that both low self perceived SES, actual SES, and multi-morbidity are independent predictors of clinically relevant depressive symptoms. The effects of low self perceived SES on depression may be stronger than the effects from objective measure of SES. Further research using a prospective design will further clarify the role of co-morbidity and in particular, self perceived SES on clinically relevant depressive symptoms and outcomes.

\section{Competing interests}

The author(s) declare that they have no competing interests.

\section{Authors' contributions}

SW participated in the design of the study and performed the statistical analysis. SM conceived of the study and participated in its design and coordination and helped to draft the manuscript and revision. JW participated in the design of study, monitored BMD measurement and participated in revision of manuscript. JL participated in statistical analysis. All authors read and approved the final manuscript.

\section{Acknowledgements}

This study is supported by the Research Grants Council of Hong Kong (CUHK 4I0I/02M).

\section{References}

I. World Health Organization: The world health report 200I mental health: new understanding, new hope. Geneva, World Health Organization 2000.

2. Adler NE, Epel E, Castellazzo G, et al.: Relationship of subjective and objective social status with psychological and physiological functioning: preliminary data in healthy white women. Health Psychol 2000, I 9:586-592.

3. Hu P, Adler NE, Goldman N, et al.: Relationship between subjective social status and measures of health in older Taiwanese persons. J Am Geriatr Soc 2005, 53:483-488.

4. Marmot M: Social determinants of health inequalities. Lancet 2005, 365:1099-I 104.

5. Buist-Boiuwman MA, de Graaf R, Vollebergh WAM, et al:: Comorbidity of physical and mental disorders and the effect on work-loss days. Acta Psychiatr Scand 2005, I I I :436-443.

6. Simon GE, Von Korff M, Saunders K, et al.: Association between obesity and psychiatric disorders in the US adult population. Arch Gen Psychiatry 2006, 63:1-7.

7. Ortega AN, Fieldman JN, Canino JN, et al.: Co-occurrence of mental and physical illness in US Latinos. Soc Psychiatry Psychiatr Epidemiol 2006, 41:927-934.

8. Scott KM, Bruffaerts $\mathrm{R}$, Tsang $\mathrm{A}$, et al.: Depression-anxiety relationships with chronic physical conditions: Results from the World Mental Health surveys. J Affective Disorders 2007.

9. Wang PS, Simon G, Kessier RC: The economic burden of depression and the cost-effectiveness of treatment. Int J Methods Psychiatr Res 2003, I 2(I):22-33.

10. Ciechanowski PS, Katon WJ, Russo JE: Depression and diabetes: impact of depressive symptoms on adherence, function, and costs. Arch Intern Med 2000, I 60(2I):3278-85.

II. Zhang JX, Ho SC, Woo J: Assessing mental health and its association with income and resource utilization in old-old Chinese in Hong Kong. Am J Geriat Psychiat 2005, I3:236-243. 
12. Evans DL, Charney DS, Lewis L, et al.: Mood disorders in the medically ill: scientific review and recommendations. Biol Psychiatry 2005, 58:175-189.

13. Lorant V, Deliege D, Eaton W, et al.: Socioeconomic inequalities in depression: a meta-analysis. Am J Epidemiol 2003, I 57:98-I I 2.

14. Stansfeld SA, Head J, Fuhrer R, et al.: Social inequalities in depressive symptoms and physical functioning in the Whitehall II study: exploring a common cause explanation. I Epidemiol Commun H 2003, 57:361-7.

15. Koster A, Bosma H, Kempen GIJM, et al: Socioeconomic differences in incident depression in older adults: the role of psychosocial factors, physical health status, and behaviora factors. J Psychosomatic Research 2006, 61:619-627.

16. Fortin M, Bravo G, Hudon $C$, et al.: Psychological distress and multi-morbidity in primary care. Ann Fam Med 2006, 4:4I 7-422.

17. Mauksch LB, Katon WJ, Russo J, et al: The content of a lowincome, uninsured primary care population: including the patient agenda. J Am Board Fam Pract 2003, 16:278-289.

18. Matheson FI, Moineddin R, Dunn JR, et al:: Urban neighbourhoods, chronic stress, gender, and depression. Soc Sci Med 2003 63:2604-2616.

19. Wong SYS, Lau EMC, Lynn H, et al.: Depression and bone mineral density: is there a relationship in elderly men? Results from Mr. Os (Hong Kong). Osteoporosis Int 2005, 16:610-615.

20. Wong SYS, Woo J, Lynn HSH, et al.: Risk of depression in patients with COPD: Results from two large cohort studies in Chinese elderly from Hong Kong. Int J of Geriatr Psychiatr 2006, 2I(3):233-8

21. Wong SYS, Hong A, Leung J, et al.: Lower urinary tract symptoms and depressive symptoms in elderly men. J Affective Disorders 2006, 96:83-88.

22. Tang WK, Ungvari GS, Chiu HF, et al:: Psychiatric morbidity in first time stroke patients in Hong Kong: a pilot study in a rehabilitation unit. Aust N Z | Psychiatry 2002, 36(4):544-9.

23. Lee HB, Chiu HFK, Kwok WY, Leung CM, Kwong PK, Chung DWS: Chinese elderly and the GDS short form: a preliminary study. Clinical Gerontologist 1993, I4(2):37-39.

24. Schultz SK: Depression in the older adults: The challenge of medical comorbidity. Am J Psychiat 2007, 164(6):847-848.

25. Delgard OS, Dowrick $C$, Lehtinen $V$, et al.: Negative life events, social support and gender difference in depression: a multinational community survey with data from the ODIN study. Soc Psychiatry Psychiatr Epidemiol 2006, 4 I (6):444-5 I.

26. Kendler KS, Thornton LM, Prescott CA: Gender differences in the rates of exposure to stressful life events and sensitivity to their depressogenic effects. Am J Psychiat 200I, I 58(4):587-93.

27. Cheng YH, Chi I, Boey KW, et al:: Self-rated economic condition and the health of elderly persons in Hong Kong. Soc Sci Med 2002, 55:1415-1424.

28. Wilkinson RG: Health, hierarchy, and social anxiety. In Socioeconomic, status and health in industrial Nations: Social, Psychological, and Biological Pathways Edited by: Adler NE, Marmot M, McEwen B et al. New York: New York Academy of Science; 1999:48-63.

29. Skapinakis P, Welch S, Lewis G, Singleton N, Araya R: Socio-economic position and common mental disorders. BrJ Psychiatry 2006, 189:109-117.

30. Kennedy BP, Kawachi I, Glass R, et al:: Income distribution, socioeconomic status, and self-rated health in the United States: Multi-level analysis. BM] 1998, 317:9|7-92।.

31. Ahrens AH, Alloy LB: Social comparison process in depression. In Health, Coping and Well-Being: Perspective from Social Comparison Theory. Edited by: Brunk BP, Gibbons FX. Mahwah, NJ: Erlbaum:389-410.

\section{Pre-publication history}

The pre-publication history for this paper can be accessed here:

http://www.biomedcentral.com/1471-2458/8/119/pre pub

\section{Publish with Bio Med Central and every} scientist can read your work free of charge

"BioMed Central will be the most significant development for disseminating the results of biomedical research in our lifetime. "

Sir Paul Nurse, Cancer Research UK

Your research papers will be:

- available free of charge to the entire biomedical community

- peer reviewed and published immediately upon acceptance

- cited in PubMed and archived on PubMed Central

- yours - you keep the copyright
BioMedcentral 